\title{
Um Survey sobre a Pertinência e Relevância de Critérios de Decisão para Apoiar o Gerenciamento de Itens de Dívida Técnica
}

\author{
Leilane Ferreira Ribeiro ${ }^{1,2}$ e Rodrigo Oliveira Spínola ${ }^{1,3}$ \\ ${ }^{1}$ Programa de Pós-Graduação em Sistemas e Computação \\ Universidade Salvador - UNIFACS, Salvador, Bahia, Brasil \\ ${ }^{2}$ Departamento de Ensino \\ Instituto Federal da Bahia - IFBA, Jequié, Bahia, Brasil \\ ${ }^{3}$ Fraunhofer Project Center at UFBA \\ Universidade Federal da Bahia, Salvador, Bahia, Brasil \\ leilaneferreira@ifba.edu.br, rodrigo.spinola@pro.unifacs.br
}

\begin{abstract}
Resumo. O termo dívida técnica (DT) é utilizado para descrever os custos de longo prazo decorrentes de atalhos tomados no desenvolvimento e evolução do software. As estratégias de gerenciamento da DT identificam itens da divida e avaliam quando e se eles devem ser pagos. Utilizar critérios de decisão pode apoiar a escolha do momento mais adequado para pagamento desses itens. No entanto, pouco ainda se sabe sobre a aplicabilidade dos critérios que têm sido propostos na literatura técnica. Nesse contexto, este trabalho apresenta os resultados de um survey que foi executado com o objetivo de caracterizar critérios de decisão identificados na literatura técnica com respeito à sua pertinência e relevância no apoio à gestão da DT. Ao total, 33 respostas foram obtidas e permitiram identificar o conjunto de critérios pertinentes, além de ordená-los pelos seus respectivos níveis de relevância.
\end{abstract}

\begin{abstract}
The technical debt (TD) concept is used to describe long-term costs of shortcuts taken during the development and evolution of the software. TD management strategies assess when and if TD items should be paid. The use of decision criteria can support the choice of the most appropriate time to pay off such items. However, little is known about the applicability of criteria that have been proposed in the technical literature. In this context, this paper presents the results of a survey that was performed in order to characterize decision criteria with respect to their pertinence and relevance in supporting the technical debt management. A total of 33 responses were received and allowed us to identify a set of pertinent criteria as well as their relevance levels.
\end{abstract}

\section{Introdução}

Equipes de desenvolvimento de software frequentemente enfrentam o desafio de entregar produtos de software sob prazos apertados enquanto lutam para manter a sua qualidade. Para lidar com o tempo e recursos disponíveis, muitas vezes, os desenvolvedores precisam fazer sacrifícios em uma dimensão do desenvolvimento (por exemplo, redução da qualidade do software), a fim de aperfeiçoar outra (por exemplo, implementação de funcionalidades necessárias para atender metas de entrega) [Zazworka et al. 2011]. Em 
tais situações, a capacidade de evoluir o software a longo prazo é muitas vezes ignorada. Como resultado, artefatos de baixa qualidade emergem, e, por sua vez, adicionam mais restrições em tarefas de desenvolvimento futuras tornando a evolução do software mais difícil, dispendiosa e imprevisível. Este fenômeno é chamado de "Dívida Técnica" [Guo et al. 2014].

Dívida técnica é uma metáfora originalmente citada em 1992 por Ward Cunningham para descrever uma situação em que a qualidade do código é deixada de lado em busca de produtividade no curto prazo [Cunningham 1992]. Assim, o termo é utilizado para se referir aos possíveis custos de longo prazo decorrentes dos atalhos tomados pela equipe durante o desenvolvimento e evolução do software para trazer benefícios no curto prazo [Ramasubbu and Kemerer 2014].

É comum que um projeto de software incorra em DT uma vez que pequenas quantidades de dívida podem ajudar a alcançar os objetivos do projeto mais rapidamente, mas para isso a equipe deve estar consciente de sua existência e deve gerencia-la adequadamente [Kruchten et al. 2012] [Spínola et al. 2013] [Guo et al. 2014]. A dívida não gerenciada pode trazer dificuldades significativas a longo prazo [Brown et al. 2010] [Spínola et al. 2013], fazendo com que projetos de software enfrentem problemas técnicos e financeiros, levando ao aumento dos custos de manutenção e evolução [Nord et al. 2012]. Power (2013) acrescenta que, se negligenciada, a DT irá, ao longo do tempo, impactar na velocidade de desenvolvimento da equipe, diminuindo a eficiência de desenvolvimento e sustentabilidade do projeto.

Estratégias de gerenciamento de DT têm sido propostas no intuito de minimizar possíveis impactos negativos do acúmulo da dívida e têm como objetivo principal avaliar o momento mais adequado para que os itens da dívida sejam eliminados do projeto [Guo et al. 2014]. Em um mapeamento sistemático recente da área, Alves et al. (2016) identificaram um conjunto de estratégias de gerenciamento de DT, contudo nenhuma delas tratou especificamente sobre critérios para apoiar a tomada de decisão sobre o momento mais adequado para pagamento da dívida. Utilizar critérios de decisão bem definidos é importante, pois auxilia a obtenção do equilíbrio entre os benefícios de curto prazo decorrentes do acúmulo da dívida, com os custos de longo prazo associados à sua presença no projeto.

Neste contexto, Ribeiro et al. (2016) realizaram uma revisão controlada da literatura com o objetivo de identificar critérios de decisão que têm sido propostos. Neste estudo foram identificados 14 critérios que podem ser utilizados para decidir e/ou priorizar o pagamento de itens de DT incorridos em projetos de software. Contudo, os critérios identificados não passaram por qualquer tipo de avaliação nos artigos identificados. Nesse contexto, este trabalho estende a pesquisa de Ribeiro et al. (2016) através da avaliação do conjunto de critérios identificados considerando a opinião de pesquisadores e profissionais da área. Para isso, foi executado um survey com o objetivo de analisar os critérios de decisão para pagamento de itens de DT, com o propósito de caracterizá-los, com respeito à pertinência e relevância no apoio à gestão de DT sob o ponto de vista de estudantes e profissionais da área de software no contexto de projetos de desenvolvimento de software. O survey foi realizado com 33 participantes de diferentes níveis de experiência. A partir de sua execução foi possível identificar o conjunto de critérios considerados pertinentes para apoiar a gestão da DT e ordená-los pelos seus respectivos níveis de relevância. 
Os resultados desta pesquisa contribuem para a evolução do technical debt landscape [Izurieta et al. 2012], além de fornecer, para profissionais da área, informações que podem ser utilizadas na definição de uma estratégia para gerenciar itens de DT em seus projetos. Os critérios estão posicionados no centro dessas estratégias, mais especificamente na atividade que apoia a decisão de quais itens da dívida devem ser pagos e em qual momento. Dessa forma, seu uso possibilitará uma tomada de decisão mais sistematizada, aprimorando a forma como a organização escolhe os itens de dívida que devem ser eliminados do projeto.

Além desta introdução, este trabalho contém outras quatro seções. A Seção 2 apresenta o referencial teórico sobre DT e sua gestão. Além disso, apresenta também os critérios identificados por Ribeiro et al. (2016) e que serão objeto de avaliação neste artigo. Em seguida, a Seção 3 detalha o planejamento, execução e resultados do survey executado. Algumas ameaças à validade são apresentadas na Seção 4. Por fim, a Seção 5 apresenta as considerações finais e os próximos passos dessa pesquisa.

\section{Dívida Técnica}

DT pode ser entendida como uma metáfora para artefatos imaturos, incompletos ou inadequados no ciclo de vida de desenvolvimento de um software. Incorrer em DT pode acelerar o desenvolvimento do software, mas esse benefício é obtido à custa de trabalho extra no futuro [Seaman and Guo 2011].

Para Mamun, Berger e Hansson (2014), a DT é uma metáfora que utiliza conceitos de dívida financeira para descrever a tendência de aumento dos custos do desenvolvimento de software ao longo do tempo. Assim como a dívida financeira, a DT incorre em pagamento de juros, que vêm na forma de esforço extra que deverá ser realizado no desenvolvimento futuro [Kruchten et al. 2013]. Apesar das semelhanças entre os conceitos utilizados, a DT não é o mesmo que dívida financeira. Algumas diferenças importantes são: uma DT deixa de existir automaticamente quando o sistema é descontinuado [Buschmann 2011], a DT pode nunca precisar ser paga [Allmam 2012], e os juros associados a ela podem ou não precisar ser pagos [Guo et al. 2014].

Alves et al. (2016) consideram DT como qualquer aspecto do software que está inadequado e que não é ajustado no momento em que é identificado, tais como documentação desatualizada, código excessivamente complexo que precisa ser refatorado e testes não realizados. Assim, a dívida pode afetar o projeto em diferentes atividades do desenvolvimento, podendo ser classificada em diferentes tipos como dívida de código, arquitetura, teste, documentação, entre outros [Alves et al. 2014].

Entre as razões para incorrer em dívida técnica podem estar prazos muitos apertados, falta de recursos e metas com alto custo [Buschmann 2011]. Dessa forma, a DT pode ser incorrida quando é preciso escolher entre desenvolver o software dentro dos padrões de qualidade ou entregá-lo no menor tempo e com o mínimo de recursos possíveis. Para Allman (2012), a DT é adquirida quando os membros da equipe tomam atalhos que ficam aquém das melhores práticas de desenvolvimento.

\subsection{Gestão de Dívida Técnica}

Nem sempre incorrer em DT é ruim. De acordo com Kruchten et al. (2012), a dívida pode ser um bom investimento desde que a equipe do projeto esteja consciente de sua existência e do aumento do desgaste que ela vai impor à equipe. Entretanto, a DT não 
gerenciada pode fazer com que os projetos de software tenham seus custos de evolução aumentados [Nord et al. 2012]. Assim, sua gestão se concentra na redução do impacto negativo da dívida e é um importante fator para o sucesso de projetos de software [Seaman and Guo 2011].

A gestão da DT compreende as ações de identificação, avaliação e pagamento da dívida que acompanha um sistema durante o seu desenvolvimento [Griffith et al. 2014]. Para Guo et al. (2014), o principal objetivo de identificar e medir a DT é viabilizar e facilitar a tomada de decisão sobre a necessidade de eliminá-la e o momento mais oportuno de fazer isso. Lim et al. (2012) afirmam que, se não for possível evitar a dívida técnica, esta deve ser gerenciada. E isto significa reconhecê-la, monitorá-la e tomar decisões fundamentadas para prevenir suas consequências negativas.

Kruchten et al. (2013) concordam que a DT não deve ser completamente eliminada. Eles afirmam, por exemplo, que pode ser um desperdício de tempo e esforço refatorar um código que está correto, mas mal organizado, se ele não precisar passar por atividades de evolução. Portanto, os desenvolvedores devem julgar e decidir quais itens de dívida devem ser pagos. Kruchten et al. (2012) sugerem que a DT deve ser mantida em um nível gerenciável, afirmando que, quando o projeto a gerencia adequadamente, ela pode ajudá-lo a alcançar seus objetivos mais rapidamente.

\subsection{Critérios de Decisão para Apoiar o Gerenciamento de Itens de Dívida}

As estratégias de gerenciamento monitoram os itens da dívida e avaliam quando e se eles devem ser pagos. Para apoiar essa avaliação, é fundamental a existência de critérios que permitam apoiar na escolha do momento mais oportuno para o pagamento de um determinado item da dívida. $\mathrm{O}$ uso desses critérios pode ajudar a equipe a padronizar o que é analisado no momento da priorização do pagamento, além de proporcionar uma maior agilidade na tomada de decisão [Ribeiro et al. 2016].

Ribeiro et al. (2016) reportaram os resultados de um mapeamento sistemático da literatura no qual identificaram 14 critérios de decisão:

- Análise de quando a parte refatorada será utilizada: itens de dívida que estão em partes muito utilizadas do sistema devem ser pagos;

- Custo/benefício: itens de dívida com má relação custo/benefício (é mais caro manter a dívida no projeto do que eliminá-la) devem ser pagos;

- Escopo de testes: itens de dívida que possuem menor escopo de testes para avaliar a sua correção devem ser priorizados;

- Esforço para implementar a proposta de correção: itens de dívida que exigem menor esforço para serem pagos devem ser eliminados primeiro;

- Existência de solução alternativa: o pagamento de dívidas que não possuem uma solução alternativa deve ser realizado;

- Gravidade da dívida: itens de dívida que possuírem nível alto de gravidade devem ser pagos;

- Impacto da dívida no projeto: itens de dívida que oferecem maior impacto para o projeto (exemplo: esforço extra para dar continuidade à evolução do software) devem ser eliminados; 
- Impacto no cliente: itens de dívida que impactam diretamente no cliente devem ser priorizados;

- Natureza do Projeto: em projetos críticos, a dívida deve ser eliminada mais rapidamente;

- Necessidade de evolução do sistema ou funcionalidade: itens de dívida presentes em sistemas estáveis ou que não irão evoluir não devem ser pagos;

- Proximidade com atividade de desenvolvimento ou manutenção atual no projeto: se a dívida está localizada em um item do projeto que será objeto de trabalho devido a uma atividade de desenvolvimento ou manutenção, o engenheiro de software deve aproveitar a atividade para pagar a dívida;

- Tempo de permanência da dívida no projeto: itens de dívida que estão há muito tempo no projeto devem ser pagos;

- Tempo de vida do sistema: itens de dívida presentes em sistemas que serão descontinuados em breve não devem ser pagos;

- Visibilidade: se o item de dívida puder ser percebido pelo usuário, então ele deve ser pago.

Apesar da importância da identificação dos diferentes critérios de decisão, Ribeiro et al. (2016) não identificaram na literatura técnica outros trabalhos focados na análise de critérios de decisão e nem qualquer evidência experimental a respeito deles. Dessa forma, identificou-se a necessidade de realizar uma avaliação considerando a visão de outros pesquisadores e profissionais da área. Para isso, optou-se pela realização de um survey cujo planejamento e resultados serão apresentados na próxima seção.

\section{Pertinência e Relevância de Critérios de Decisão para Apoiar o Gerenciamento de Itens de Dívida Técnica}

O objetivo do survey apresentado neste trabalho é analisar os critérios de decisão para gerenciamento de itens de dívida técnica identificados por Ribeiro et al. (2016), com o propósito de caracterizá-los, com respeito à sua pertinência e relevância no apoio à gestão de dívida técnica sob o ponto de vista de estudantes e profissionais no contexto de projetos de desenvolvimento de software.

O planejamento e execução deste survey, incluindo a definição de varíaveis, hipóteses, instrumentação e análise dos dados, foram fundamentados nos estudos descritos em [Dias-Neto and Travassos 2008] e [Spínola and Travassos 2012]. Assim, inicialmente foram definidas as seguintes questões de pesquisa:

- Os critérios de decisão extraídos da literatura são pertinentes para apoiar a decisão sobre o pagamento de itens da dívida técnica?

- Existem critérios de decisão descritos no corpo de conhecimento que foram incluídos indevidamente no conjunto de critérios e que deveriam ser excluídos?

- Existem critérios de decisão que devem ser incluídos no conjunto de critérios de decisão descritos no corpo de conhecimento? 
- Qual é o nível de relevância dos critérios de decisão considerando o apoio à decisão sobre o pagamento de itens da dívida presentes em projetos de software?

Neste estudo, entende-se que um critério é pertinente quando ele é importante para apoiar a tomada de decisão sobre o pagamento de um item de dívida técnica. Já a relevância de um critério indica o quão importante ele é no momento da decisão sobre o pagamento de um item da dívida. Foram definidas as seguintes variáveis para o estudo:

\section{Variáveis relacionadas à pertinência dos critérios de decisão}

$\mathbf{C}_{\mathbf{C I}}=$ Conjunto inicial dos critérios de decisão.

$\mathbf{C}_{\mathbf{I N}}=$ Critérios de decisão a serem incluídos em $\mathrm{C}_{\mathrm{CI}}$.

$\mathbf{C}_{\mathbf{E X}}=$ Critérios de decisão a serem excluídos de $\mathrm{C}_{\mathrm{CI}}$.

$\mathbf{C}_{\mathbf{F}}=$ Conjunto final de critérios de decisão.

\section{Variáveis relacionadas à relevância dos critérios de decisão}

$\mathbf{R E i}$ = nível de relevância do critério " $i$ " considerando o apoio fornecido na decisão sobre o pagamento de itens da dívida, onde "i" se refere a um numero de 1 a n (sendo n o numero total de critérios de decisão).

Foram definidas também duas hipóteses nulas que estão relacionadas, respectivamente, à análise da pertinência dos critérios $(\mathrm{H} 0-1)$ e de suas relevâncias para apoiar a tomada de decisão sobre o pagamento da dívida (H0-2). Elas são descritas a seguir, junto com suas hipóteses alternativas:

Hipótese nula 1 (H0-1): o conjunto inicial de critérios de decisão é completo, ou seja, não existem critérios de decisão a serem incluídos nem excluídos de $\mathrm{C}_{\mathrm{CI}}$.

$$
\text { H0-1: } \mathrm{C}_{\mathrm{IN}}=\mathrm{C}_{\mathrm{EX}}=\varnothing ; \mathrm{C}_{\mathrm{F}}=\mathrm{C}_{\mathrm{CI}}
$$

Hipótese Alternativa (H1): o conjunto inicial de critérios de decisão é incompleto, ou seja, existe pelo menos um critério de decisão a ser incluído em $\mathrm{C}_{\mathrm{CI}}$.

$$
\mathrm{H} 1: \mathrm{C}_{\mathrm{IN}} \neq \varnothing ; \mathrm{C}_{\mathrm{F}}=\mathrm{C}_{\mathrm{CI}}+\mathrm{C}_{\mathrm{IN}}
$$

Hipótese Alternativa (H2): existe pelo menos um critério de decisão a ser excluído de $\mathrm{C}_{\mathrm{CI}}$.

$$
\mathrm{H} 2: \mathrm{C}_{\mathrm{EX}} \neq \varnothing ; \mathrm{C}_{\mathrm{F}}=\mathrm{C}_{\mathrm{CI}}-\mathrm{C}_{\mathrm{EX}}
$$

Hipótese nula 2 (H0-2): os critérios de decisão para apoiar a tomada de decisão sobre o pagamento de itens da dívida possuem o mesmo nível de relevância.

$$
\mathrm{H} 0-2: \mathrm{RE}_{1}=\mathrm{RE}_{2}=\mathrm{RE}_{3}=\ldots=\mathrm{RE}_{\mathrm{n}}
$$

Hipótese alternativa 3 (H3): os critérios de decisão para apoiar a tomada de decisão sobre o pagamento de itens da dívida não possuem o mesmo nível de relevância.

$$
\begin{gathered}
H 3: \exists R E_{i} \mid R E_{i} \neq R E_{j}, i \neq j \\
\text { (onde “ij” e "j” são números entre } 1 \text { e n, e “ij” } \neq \text { “j”) }
\end{gathered}
$$

\subsection{Planejamento da Instrumentação e População}

A população deste survey foi escolhida por conveniência e considerou os participantes de dois eventos sobre DT realizados em ambiente acadêmico e na indústria. Todo o contato 
com os participantes foi realizado presencialmente, incluindo o preenchimento do questionário.

Para apoiar a execução deste survey, o estudo foi composto por:

- Formulário de consentimento: que indicava a concordância dos participantes em participar do estudo;

- Formulário de caracterização: que permite identificar características da população envolvida no preenchimento dos questionários. Os participantes foram questionados a respeito de seus dados pessoais, formação acadêmica, nível de experiência na indústria (em anos), papéis desempenhados, experiência em desenvolvimento de projetos de software (em anos), conhecimento sobre refatoração, code smells e DT;

- Glossário: contendo a descrição de cada um dos critérios de decisão avaliados no estudo;

- Questionário de avaliação: no qual os participantes indicam a pertinência e a relevância dos critérios analisados. Seu preenchimento é realizado em três etapas:

(1) Identificação dos critérios pertinentes para apoiar a decisão sobre o pagamento de DT: nesta etapa, os participantes foram solicitados a indicar quais critérios consideravam pertinentes;

(2) Definição do nível de relevância dos critérios de decisão para apoiar a tomada de decisão sobre o pagamento do item de dívida: para esta etapa (Figura 1), foram considerados cinco níveis de relevância a serem definidos para cada um dos critérios identificados:

- Irrelevante: é o nível mais baixo de relevância e indica que o critério de decisão não afeta a decisão sobre o pagamento da dívida técnica;

- Relevância Baixa: indica que o critério de decisão pode não afetar a decisão sobre o pagamento da dívida técnica;

- Relevância Média: indica que o critério de decisão afeta a decisão sobre o pagamento da dívida técnica dependendo da aplicação. Em algumas aplicações o critério pode ser mais relevante;

- Relevância Alta: indica que o critério de decisão deve ser levado em consideração na tomada de decisão sobre o pagamento da dívida técnica;

- Relevância Muito Alta: indica que o critério de decisão é absolutamente necessário ao se tomar uma decisão quanto ao pagamento de uma dívida técnica.

(3) Identificação de novos critérios: ao final, o participante foi solicitado a incluir possíveis critérios que julgasse importantes, mas que não constavam na lista inicial. 


\begin{tabular}{|c|c|c|c|c|c|}
\hline & Irrelevante & Baixo & Médio & Alto & Muito alto \\
\hline Gravidade da Dívida & [ ] & [ ] & [ ] & [ ] & [ ] \\
\hline Existência de solução alternativa & [ ] & [ ] & [ ] & [ ] & [ ] \\
\hline Tempo de permanência da dívida no projeto & [ ] & [ ] & [ ] & [ ] & [ ] \\
\hline $\begin{array}{l}\text { Proximidade com atividade de desenvolvimento ou } \\
\text { manutenção atual no projeto }\end{array}$ & [ ] & [ ] & [ ] & [ ] & [ ] \\
\hline Visibilidade & [ ] & [ ] & [ ] & [ ] & [ ] \\
\hline Análise de quando a parte refatorada será utilizada & [ ] & [ ] & [ ] & [ ] & [ ] \\
\hline Impacto no cliente & [ ] & [ ] & [ ] & [ ] & [ ] \\
\hline Impacto da dívida no projeto & [ ] & [ ] & [ ] & [ ] & [ ] \\
\hline Escopo de testes & [ ] & [ ] & [ ] & [ ] & [ ] \\
\hline Custo/benefício & [ ] & [ ] & [ ] & [ ] & [ ] \\
\hline Esforço para implementar a proposta de correção & [ ] & [ ] & [ ] & [ ] & [ ] \\
\hline Natureza do Projeto & [ ] & [ ] & [ ] & [ ] & [ ] \\
\hline Tempo de vida do sistema & [ ] & [ ] & [ ] & [ ] & [ ] \\
\hline Necessidade de evolução do Sistema/ Funcionalidade & [ ] & [ ] & [ ] & [ ] & [ ] \\
\hline
\end{tabular}

3. Você acrescentaria algum critério de decisão? *

[ ] Sim, Quais?

[ ] Não $\quad$ Obrigado!

Figura 1. Indicação do nível de relevânica dos critérios de decisão.

\subsection{Planejamento da Análise de dados}

Para a análise dos dados coletados com a execução do questionário, foi preciso definir como seriam calculadas a pertinência dos critérios e seus respectivos níveis de relevância.

\subsubsection{Pertinência dos critérios}

Para definir quais critérios são pertinentes, é necessário primeiro somar as respostas de cada participante:

$$
\operatorname{Pertinência}(j)=\sum_{i=1}^{M}(\operatorname{Re} \operatorname{sposta}(i, j)) \text {, onde: }
$$

- Pertinência $(j)$ é o valor total das respostas de todos os participantes sobre a pertinência do critério $j$ para apoiar a decisão sobre o pagamento de dívida técnica;

- Re $\operatorname{sposta}(i, j)$ indica se o critério $j$ foi definido pelo participante $i$ como pertinente (1) ou não pertinente (0);

- Mé o número total de participantes do survey.

A definição se o critério de decisão é ou não pertinente é baseada em um ponto de corte (limite) que indica se um determinado critério é incluído (valor maior do que o limite) ou não (valor menor do que o limite) no conjunto final de critérios de decisão. Baseado em [Dias-Neto and Travassos, 2008] e [Spínola and Travassos, 2012], o valor definido como limite foi $50 \%$ do valor máximo que um critério $j$ pode obter na variável se todos os participantes o classificarem como pertinente. Assim,

$$
\text { Limite }=0,5^{*} \sum_{i=1}^{M} \text {, onde } M \text { é o número total de participantes do survey. }
$$


Dessa forma, o critério $j$ é classificado como "pertinente" e deve ser mantido no conjunto se Pertinência $(j) \geq$ Limite, e é classificado como "não pertinente" e deve ser removido do conjunto se Pertinência $(j)<$ Limite .

\subsubsection{Relevância dos critérios}

Para definir o nível de relevância de cada critério de decisão classificado como pertinente, é necessário primeiro somar as respostas de cada participante. Dessa forma, a seguinte fórmula será considerada:

$$
\operatorname{Re} \operatorname{levância}(j)=\sum_{i=1}^{N}(\operatorname{Nivel}(i, j)), \text { onde: }
$$

- Relevância $(j)$ é o valor total das respostas de todos os participantes para o critério $j$

- $\quad$ Nível $(i, j)$ é a escala de nível de relevância (1-5) definida pelo participante $i$ para o critério $j$;

- $\quad$ é o número total de participantes do survey.

Após calcular o nível de relevância de cada critério, eles serão ordenados do nível de relevância mais alto para o mais baixo. Os critérios mais relevantes são os que possuem maior valor para Relevância $(j)$.

\subsection{Resultados}

\subsubsection{Caracterização dos participantes}

O survey foi aplicado em dois eventos sobre DT. No primeiro, o questionário foi entregue aos participantes de uma palestra ministrada na Universidade Federal da Bahia e, no segundo, foi aplicado aos participantes de um Workshop no Parque Tecnológico da Bahia. Ao total, estes eventos reuniram 33 participantes, no ano de 2015, que contribuíram de forma espontânea com a realização do estudo.

Entre os 33 participantes, $17 \%$ mencionaram já ter tido experiência com atividades de gerência de projetos, $4 \%$ de gerência de configuração, $61 \%$ como programadores, $4 \%$ como designer, $26 \%$ como analistas de requisitos, $9 \%$ como analistas de controle de qualidade, $17 \%$ como produtores de site e $26 \%$ como líderes técnicos. Identificou-se também que a experiência de trabalho na indústria variava entre 4 e 13 anos, enquanto a experiência com desenvolvimento de software se encontra na faixa de 4 a 20 anos. Por fim, 88\% dos participantes afirmaram conhecer refatoração e apenas $50 \%$ conhecem Code Smell. Quanto a DT, 60\% dos participantes afirmaram ter um bom conhecimento sobre dívida técnica, 20\% indicaram já ter ouvido falar ou lido a respeito, enquanto os outros $20 \%$ afirmaram não ter conhecimento sobre DT.

\subsubsection{Os critérios de decisão extraídos da literatura são pertinentes para apoiar a decisão sobre o pagamento de itens da dívida técnica?}

Para encontrar a pertinência dos critérios de decisão e o limite inferior de pertinência, foram aplicadas as fórmulas apresentadas na seção 3.2.1. Para que um critério seja considerado pertinente, ele deve atingir $50 \%$ do valor máximo que um critério pode obter se todos os participantes o classificarem como pertinente. Esse limite foi adotado por ser 
o ponto médio na escala de nível de pertinência (que varia de $0 \%$ a $100 \%$ ). Após a execução dos cálculos para avaliar a pertinência de um critério, a seguinte fórmula foi aplicada para que fosse possível calcular a porcentagem de participantes que indicou cada critério como pertinente: Pertinência $(j) * 100 /$ totalParticipantes . Os resultados obtidos são apresentados no gráfico da Figura 2.

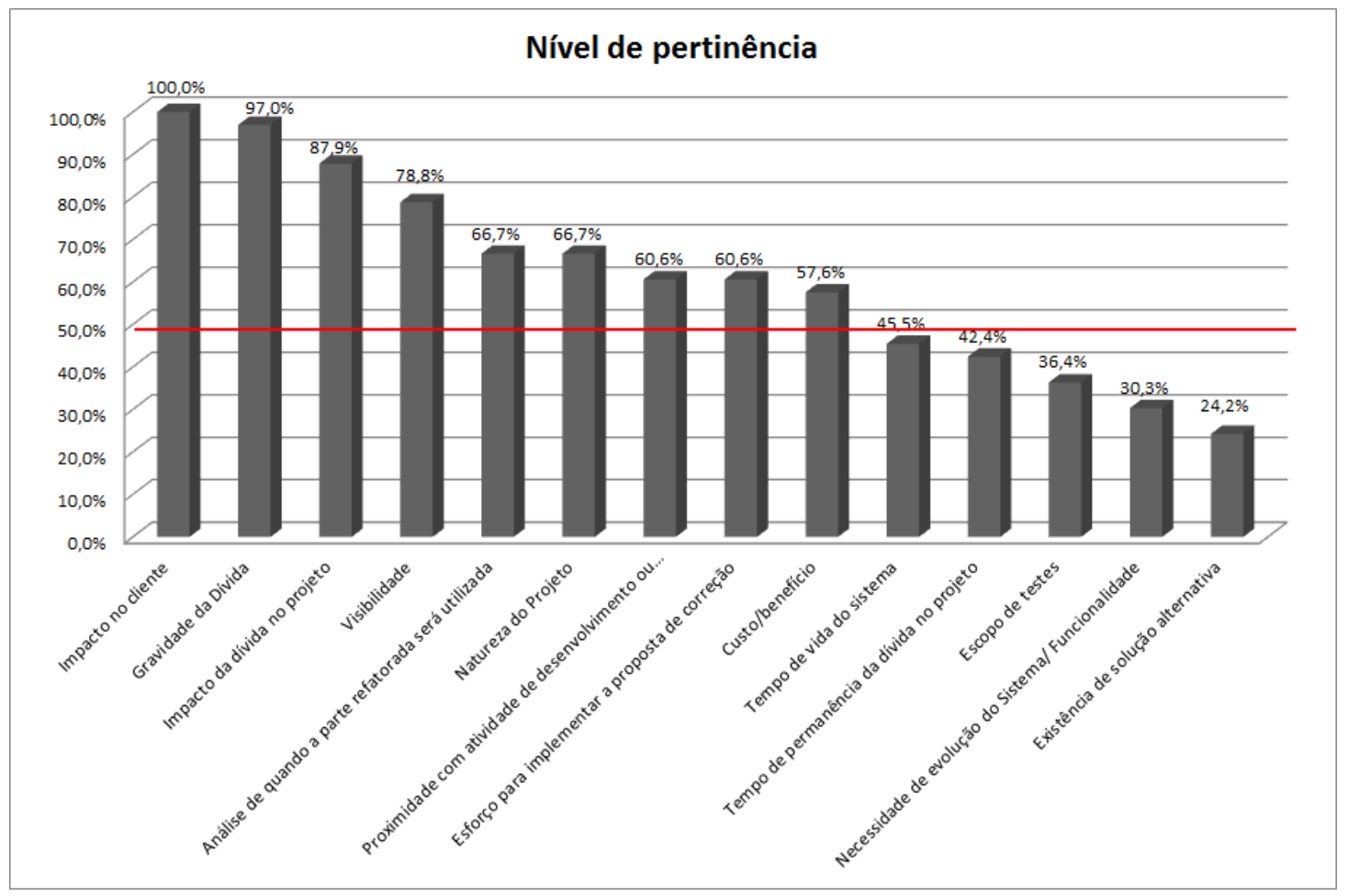

Figura 2. Nível de pertinência dos critérios de decisão.

Observando o limite ilustrado no gráfico, conclui-se que os critérios Existência de solução alternativa, Necessidade de evolução do sistema, Escopo de testes, Tempo de permanência no projeto e Tempo de vida do sistema devem ser excluídos da lista inicial de critérios considerados pertinentes. Em complemento, nenhum participante sugeriu a inclusão de um novo critério à lista inicial. Dessa forma, a Hipótese Nula 1 (H0-1) foi refutada, pois existiram critérios de decisão a serem excluídos do conjunto inicial.

Os resultados também indicaram que os critérios relacionados ao impacto que uma dívida pode ter no usuário (1-Impacto no cliente e 4-Visibilidade) estão entre os quatro mais pertinentes. Além deles, os critérios 2-Gravidade da divida e 3-Impacto da dívida (ambos referentes às dificuldades adicionais que a dívida pode trazer para a evolução do software) completam a lista dos itens que tiveram maior índice de pertinência. Essa informação indica que, normalmente, aspectos que afetam o cliente ou fazem referência ao impacto da dívida no projeto tendem a ser considerados válidos para apoiar a decisão sobre o pagamento de itens da dívida. 


\subsubsection{Qual é o nível de relevância dos critérios de decisão considerando o apoio à decisão sobre o pagamento de itens da dívida presentes em projetos de software?}

Identificados os critérios de decisão considerados pertinentes pelos participantes do estudo, o próximo passo foi a definição dos níveis de relevância para a utilização na gestão da dívida técnica. Os resultados apresentados no gráfico da Figura 3 foram obtidos após aplicar a fórmula para cálculo do nível de relevância apresentada na seção 3.2.2 e calcular a porcentagem que esse valor representa do máximo que ele pode atingir no nível de relevância. Esse último cálculo foi realizado considerando a seguinte fórmula: Relevância $(j) * 100 /$ valorMáximo.

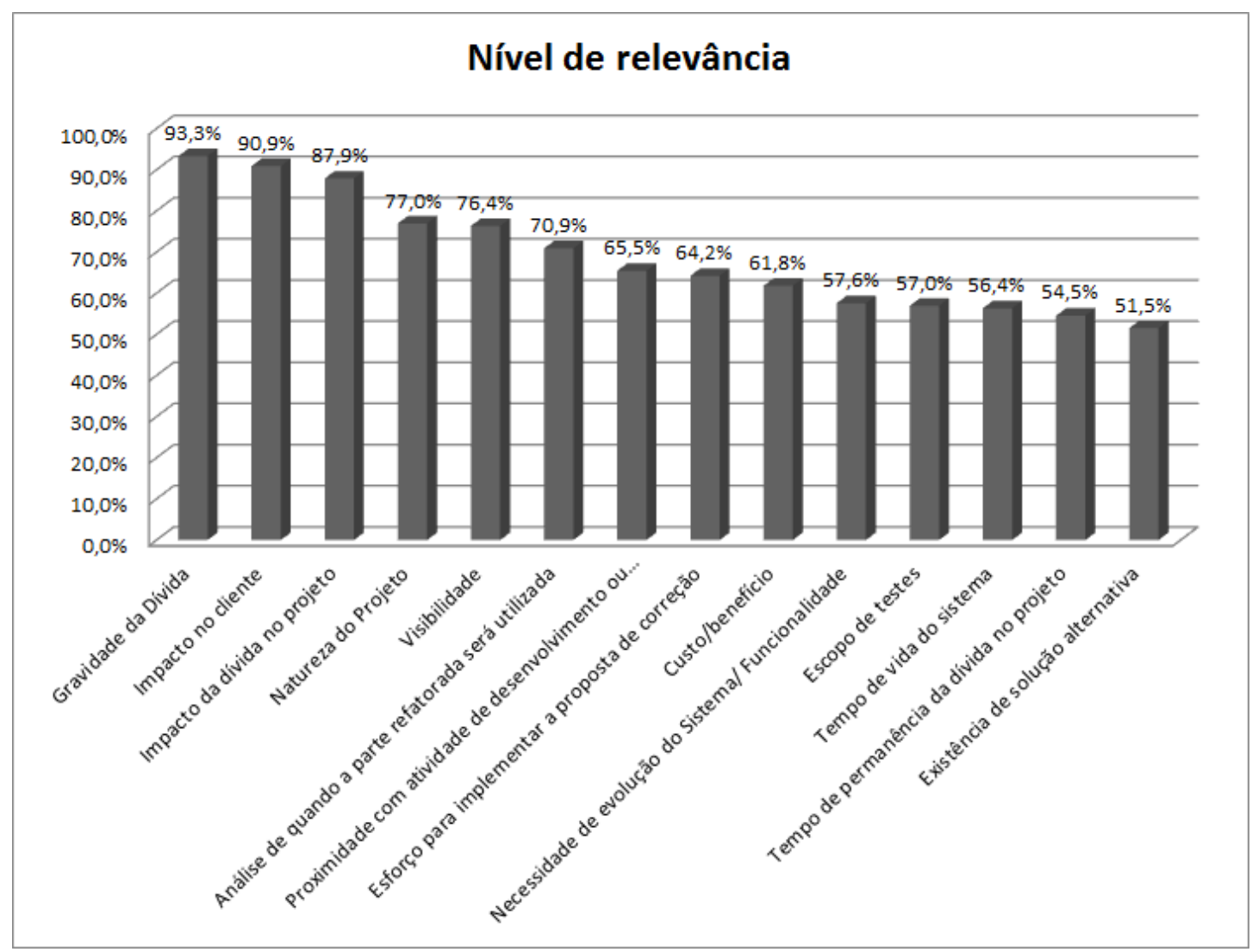

Figura 3. Nível de relevância dos critérios de decisão.

É possível notar que a Hipótese Nula 2 (H0-2) também foi refutada, uma vez que existiram critérios com diferentes níveis de relevância. A Tabela 1 apresenta um resumo da avaliação dos critérios quanto a sua pertinência e o seu nível de relevância. Analisando os dados, conclui-se que os critérios Impacto no cliente e Gravidade da divida são considerados os mais pertinentes e relevantes. É importante observar também que a ordem dos critérios pela pertinência e pelo nível de relevância se assemelha bastante, indicando que houve coerência nas respostas dos participantes para essas duas questões. Os critérios relacionados ao impacto que a dívida traz para o cliente (Impacto no cliente, Visibilidade e Análise de quando a parte refatorada será utilizada), além de estarem entre os critérios mais pertinentes, também estão posicionados entre os critérios mais relevantes. Isso indica que os aspectos que afetam o cliente são os que mais preocupam os profissionais no momento da decisão sobre o pagamento de itens da DT de um projeto. O critério 
Gravidade da dívida foi considerado o segundo mais pertinente e o primeiro no ranking de relevância. Além disso, o critério Impacto da dívida no projeto também ficou posicionado entre os três considerados mais pertinentes e relevantes. Isso indica que explorar os recursos que a dívida afeta e como ela os afeta também é importante para decidir se um determinado item de dívida deve ser pago.

As linhas destacadas em cinza ao final da tabela indicam que os critérios Tempo de vida do sistema, Tempo de permanência no projeto, Escopo de teste, Necessidade de evolução do sistema e Existência de solução alternativa não foram considerados pertinentes por pelo menos $50 \%$ dos participantes e, por isso, foram excluídos do conjunto final de critérios. No ranking de relevância dos critérios, eles também ocuparam os últimos lugares.

Tabela 1. Pertinência e relevância dos critérios de decisão.

\begin{tabular}{l|r|r|r|r}
\multicolumn{1}{c}{ Critério } & \multicolumn{1}{c|}{ Pertinência } & Rank & Relevância & Rank \\
\hline Impacto no cliente & $100,0 \%$ & $1^{\circ}$ & $90,9 \%$ & $2^{\circ}$ \\
\hline Gravidade da Dívida & $97,0 \%$ & $2^{\circ}$ & $93,3 \%$ & $1^{\circ}$ \\
\hline Impacto da dívida no projeto & $87,9 \%$ & $3^{\circ}$ & $87,9 \%$ & $3^{\circ}$ \\
\hline Visibilidade & $78,8 \%$ & $4^{\circ}$ & $76,4 \%$ & $5^{\circ}$ \\
\hline Análise de quando a parte refatorada será utilizada & $66,7 \%$ & $5^{\circ}$ & $70,9 \%$ & $6^{\circ}$ \\
\hline Natureza do Projeto & $66,7 \%$ & $6^{\circ}$ & $77,0 \%$ & $4^{\circ}$ \\
\hline $\begin{array}{l}\text { Proximidade com atividade de desenvolvimento ou } \\
\text { manutenção atual no projeto }\end{array}$ & $60,6 \%$ & $7^{\circ}$ & $65,4 \%$ & $7^{\circ}$ \\
\hline Esforço para implementar a proposta de correção & $60,6 \%$ & $8^{\circ}$ & $64,2 \%$ & $8^{\circ}$ \\
\hline Custo/benefício & $57,6 \%$ & $9^{\circ}$ & $61,8 \%$ & $9^{\circ}$ \\
\hline Tempo de vida do sistema & $45,4 \%$ & $10^{\circ}$ & $56,4 \%$ & $12^{\circ}$ \\
\hline Tempo de permanência da dívida no projeto & $42,4 \%$ & $11^{\circ}$ & $54,5 \%$ & $13^{\circ}$ \\
\hline Escopo de testes de evolução do Sistema e/ou & $36,3 \%$ & $12^{\circ}$ & $57,0 \%$ & $11^{\circ}$ \\
\hline $\begin{array}{l}\text { Necessidade de } \\
\text { funcionalidade }\end{array}$ & $24,2 \%$ & $14^{\circ}$ & $51,5 \%$ & $14^{\circ}$ \\
\hline Existência de solução alternativa & & & $10^{\circ}$ \\
\hline
\end{tabular}

\subsection{Discussão}

Os resultados deste estudo têm implicações para profissionais, principalmente para aqueles que buscam informação sobre como gerenciar a dívida em seus projetos:

- Nove critérios de decisão foram identificados como pertinentes para apoiar a gestão da DT e para ajudar a equipe a decidir e/ou priorizar o pagamento de itens de dívida incorridos nos projetos;

- Embora a definição de qual critério utilizar e seu peso no processo de tomada de decisão seja uma decisão da equipe do projeto, a ordem de relevância identificada nesta pesquisa pode auxiliar as equipes na escolha de quais critérios utilizar ou, se optarem por definir um novo critério, qual caminho seguir (uma vez que foi identificado que critérios normalmente associados ao impacto da dívida no cliente ou nas atividades do projeto são considerados pertinentes). 
Os resultados alcançados também podem orientar futuras pesquisas. Foram identificados diferentes critérios para apoiar a decisão quanto ao pagamento da dívida técnica, mas não foi identificada qualquer evidência de como eles podem ser utilizados em conjunto para apoiar a gestão da DT. Além disso, pode-se também investigar qual seria o momento mais adequado para uso de uma estratégia baseada em critérios para gerenciamento de dívida no contexto de um processo de desenvolvimento de software e qual impacto essa nova atividade traria para a equipe de desenvolvimento.

\section{Ameaças à Validade}

\subsection{Validade interna}

A má instrumentação pode ser considerada uma validade interna da pesquisa. Para mitiga-la, foi realizada uma revisão do questionário quanto ao formato e à formulação das perguntas, além de avaliação do questionário por outros pesquisadores. A comunicação entre os participantes também pode influenciar nos resultados. Para evitar essa ameaça, dois pesquisadores observaram a execução operação do experimento.

\subsection{Validade de conclusão}

Hipótese Nula 1: a verificação da hipótese nula 1 será feita por meio de simples demonstração de presença ou não de critérios de decisão a serem incluídos ou excluídos da lista de critérios. O conjunto de critérios de decisão final foi definido da seguinte forma: o conjunto de critérios de decisão inicial será modificado acrescentando-se os critérios pertencentes à lista de critérios de decisão a serem incluídos e retirando-se de critérios de decisão pertencentes à lista de critérios a serem excluídos. O resultado dessas duas operações deu origem ao conjunto final de critérios de decisão. O critério utilizado na definição dos elementos de cada uma das listas (critérios de decisão a serem incluídos e excluídos) foi definido na seção 3.2.

Hipótese Nula 2: a verificação da hipótese nula 2 foi feita por meio de simples verificação se todas os critérios de decisão possuem o mesmo nível de relevância na tomada de decisão do pagamento de dívida técnica. A forma como o cálculo do nível de relevância foi executado foi apresentada na seção 3.2.

\subsection{Validade externa}

Embora a população tenha sido escolhida por conveniência, ela foi composta por participantes da indústria e da academia com diferentes níveis de experiência, formação e área de atuação. Além disso, os participantes demonstraram interesse pelo tema pesquisado ao se inscreverem nos eventos sobre DT. Ainda que os resultados não possam ser generalizados, eles fornecem indicadores iniciais válidos sobre as hipóteses analisadas.

O objeto utilizado no estudo (conjunto de critérios de decisão) pode ser considerado atual e representativo para o problema em análise, uma vez que foi definido tendo como base um mapeamento sistemático da literatura realizado no ano de 2015.

\section{Considerações finais}

Este artigo apresentou a avaliação do corpo de conhecimento organizado por Riberio et al. (2016). Essa avaliação foi realizada através do planejamento e execução de um survey, 
cujos resultados forneceram evidências de que os critérios de decisão podem apoiar a gestão da dívida técnica, auxiliando profissionais no processo de tomada de decisão quanto ao pagamento dos itens de DT presentes no projeto. Ao final, foi obtida uma lista de critérios considerados pertinentes e o nível de relevância de cada um deles.

Como trabalho futuro, os resultados alcançados serão utilizados na definição de uma abordagem baseada em critérios para apoiar o gerenciamento de itens da DT em projetos de software. Nessa abordagem, ao detectar um item de DT no projeto, o responsável irá classificar o item considerando o conjunto de critérios de decisão, os quais poderão possuir pesos diferentes por projeto. Com os itens classificados, a abordagem possibilitará ordená-los considerando a configuração de critérios realizada. Isso permitirá uma análise mais consistente dos diferentes itens de dívida e possibilitará que ela seja realizada repetidas vezes ao longo do processo de desenvolvimento. Também como trabalho futuro, a lista de critérios de decisão será disponibilizada em TD Wiki [Alves et al. 2015].

\section{Agradecimentos}

Este trabalho foi parcialmente apoiado pelo projeto CNPq Universal 458261/2014-9. Os autores também gostariam de agradecer aos colegas Mário Farias e Nicolli Rios pelas contribuições realizadas no texto deste artigo.

\section{Referências}

Al Mamun, M., Berger, C., Hansson, J. (2014) Explicating, Understanding and Managing Technical Debt from Self-Driving Miniature Car Projects, 30th IEEE International Conference on Software Maintenance and Evolution (ICSME).

Allman, E., (2012) Managing Technical Debt, Queue 10(3).

Alves, N.S.R., Mendes, T. S., de Mendonça, M. G., Spínola, R. O., Shull, F., \& Seaman, C. (2016) Identification and management of technical debt: A systematic mapping study. Information and Software Technology, 70, 100-121.

Alves, N.S.R., Ribeiro, L.F., Caires, V., Mendes, T.S., and Spínola, R.O, (2014) Towards an Ontology of Terms on Technical Debt. In: Sixth International Workshop on Managing Technical Debt, IEEE, 1-7.

Alves, N.S.R., Araújo, R.S., Spínola, R.O. (2015) A Collaborative Computational Infrastructure for Supporting Technical Debt Knowledge Sharing and Evolution. In: Americas Conference on Information Systems.

Brown, N., Cai, Y., Guo, Y., Kazman, R., Kim, M., Kruchten, P., Lim, E., MacCormack, A., Nord, R., Ozkaya, I., Sangwan, R., Seaman, C., Sullivan, K., Zazworka, N., (2010) Managing technical debt in software-reliant systems, Proceedings of the FSE/SDP Workshop on Future of Soft. Eng. research, ACM.

Buschmann, F., (2011) To Pay or Not to Pay Technical Debt, IEEE Software.

Dias Neto, A.C.; Travassos, G.H.. (2008) Surveying Model Based Testing Approaches Characterization Attributes. In: International Symposium on Empirical Software Engineering and Measurement (ESEM), Kaiserslautern. 
Griffith, I., Izurieta, C., Taffahi, H., Claudio, D., (2014) A simulation study of practical methods for technical debt management in agile software development, in Proceedings of the 2014 winter simulation conference, Piscataway, NJ, USA.

Guo, Y., Spínola, R.O., Seaman, C. (2014) "Exploring the costs of technical debt management - a case study," Empirical Software Engineering, v. 1, p. 1-24.

Izurieta, C., Vetró, A., Zazworka, N., Cai, Y., Seaman, C., Shull, F. (2012) “Organizing the Technical Debt Landscape," in 3rd International Workshop on Managing Technical Debt, Zurich, Switzerland, June 2-9.

Kruchten, P., et al., (2013) Technical debt: towards a crisper definition report on the 4th international workshop on managing technical debt, ACM SIGSOFT Software Engineering Notes.

Kruchten, P., Nord, R. L., Ozkaya, I., (2012) Technical Debt: From metaphor to theory and practice, IEEE Software.

Lim, E., Taksande, N., Seaman, C., (2012) A Balancing Act: What Software Practitioners Have to Say About Technical Debt, Software, IEEE 29(6), 22-27.

Nord, R.; Ozkaya, I.; Kruchten, P. \& Gonzalez-Rojas, M., (2012) In Search of a Metric for Managing Architectural Technical Debt, WICSA/ECSA 2012, IEEE CS.

Power, K. (2013), Understanding the impact of technical debt on the capacity and velocity of teams and organizations: Viewing team and organization capacity as a portfolio of real options, Managing Technical Debt (MTD).

Ramasubbu, N. \& Kemerer, C.. (2014) Managing Technical Debt in Enterprise Software Packages, Software Engineering, IEEE Transactions on 40(8), 758-772.

Ribeiro, L., Farias, M., Mendonça, M., Spínola, R.O. (2016) Decision Criteria for the Payment of Technical Debt in Software Projects: A Systematic Mapping Study. In Proceedings of the 18th International Conference on Enterprise Information Systems (ICEIS) - Volume 1, pages 572-579.

Seaman, C. \& Guo, Y. (2011), Measuring and Monitoring Technical Debt, Advances in. Computers, vol. 82.

Spínola, R.O. \& Travassos, G.H. (2012) Towards a framework to characterize ubiquitous software projects, Information and Software Technology, Volume 54, Issue 7, Pages 759-785, ISSN 0950-5849, http://dx.doi.org/10.1016/j.infsof.2012.01.009.

Spínola, R.O., Zazworka, N., Vetró, A., Seaman, C., Shull, F. (2013) Investigating technical debt folklore: Shedding some light on technical debt opinion. In 4th International Workshop on Managing Technical Debt, 1-7.

Zazworka, N.; Shaw, M. A.; Shull, F., Seaman, C. (2011) Investigating the impact of design debt on software quality, Proceedings of the 2nd Workshop on Managing Technical Debt, Pages 17-23. 